\title{
How Politics Influence Public Good Provision*
}

\author{
Vitezslav Titl Kristof De Witte $^{\ddagger}$
}

November 5, 2020

\begin{abstract}
Ideological stance of politicians might play a role in the efficiency of service provision as well as in the global spending efficiency. This paper examines whether the shares of left-wing, populist, and extremist councillors on all regional councillors are associated with a higher or lower efficiency of education, healthcare, and infrastructure provision as well as with the global spending efficiency of regional governments. To calculate efficiency in each policy domain, we use conditional non-parametric efficiency models and adjust the outputs for the quality of the service provision. Subsequently, we use a composite indicator to obtain the global spending efficiency. On a rich panel dataset of Czech regional governments in the period between 2007 and 2017, we find that the share of left-wing members in the regional councils is negatively associated with the global spending efficiency. This global negative relationship appears to driven by the low performance in health provision, which outweighs a good performance in education. Finally, while we do not find any significant relationship between the share of populist councillors in the councils and the global spending efficiency, we find a significant and negative relationship between this share and the efficiency of education provision.
\end{abstract}

Keywords: Political Parties, Populism, Regional Government Efficiency, Non-parametric efficiency analysis

JEL Codes: H57, D72, C23

*We gratefully acknowledge insightful comments and suggestions from Benny Geys, Giovanna D'Inverno, Joana Maldonado, Anna Mergoni, Massimo Morelli, Jasmina Berbegal-Mirabent, Esteban Lafuente and seminar participants at KU Leuven, and the '7th International Workshop on Efficiency in Education, Health and other Public Services'. Authors also gratefully acknowledge financial support from FWO Vlaanderen (grant number G068518N).

${ }^{\dagger}$ Electronic address: vitezslav.titl@kuleuven.be; Utrecht University School of Economics, Utrecht University; Leuven Education Economics Research (LEER), Faculty of Economics and Business, KU Leuven

${ }_{\ddagger}^{\ddagger}$ Electronic address: kristof.dewitte@kuleuven.be; Leuven Education Economics Research (LEER), Faculty of Economics and Business, KU Leuven; UNU-MERIT, Maastricht University 


\section{Introduction}

General government expenditure in OECD countries is equivalent to, on average, $43 \%$ of GDP (OECD, 2019). A cost-effective management of the public sector's resources is, thus, a first-order issue. In this paper, we study how the global spending efficiency as well as the efficiency of the education, healthcare, and infrastructure provisions are associated with the political affiliations of councillors in the Czech regions, specifically, with the shares of councillors from left-wing, populist, and extremist parties on the total number of councillors.

Since Hibbs (1977), it is often argued that macroeconomic policies and outcomes associated with left and right-wing governments differ. Left lining politicians are likely to prefer more egalitarian policies, and thus, will prefer different spending priorities (for a similar line of arguments, see also Geys and Revelli, 2009). This observation is supported by the findings of Cusack (1997) who shows that left-wing political parties tend to increase public spending. This suggests that left-wing politicians might focus on high provision of public good under any circumstances ${ }^{1}$ and less on efficiency, and therefore, we expect that a higher share of left-wing councillors is associated with lower efficiency scores.

The existing evidence on the relationship between the presence of left-wing politicians and efficiency is so far rather mixed. De Witte and Geys (2011) study the efficiency of public good provision by the Flemish public libraries and find that left-wing councils are associated with a statistically significantly higher level of public good provision efficiency. On a sample of Bavarian municipalities, Asatryan and De Witte (2015) find an ambiguous statistically insignificant association between the efficiency and the share of votes for left-wing parties in 2000 Bavarian municipalities. In the first part of the paper, we re-examine this question, and in contrast to De Witte and Geys (2011), we also study the global spending efficiency (i.e. we do not focus on one service type only).

Next to left-wing parties, we focus on populist parties, which share as a common denominator their anti-elite rhetoric (Guiso et al., 2017). ${ }^{2}$ The anti-elite rhetoric seems to be one of the reasons why populist political parties tend to attract less managerial skilled public servants. The influx of inexperienced officials caused by the anti-establishment demands of populist politicians has been documented, for example, in the United States and

\footnotetext{
${ }^{1}$ See D'Inverno and De Witte (2020) for empirical evidence that a higher level of municipal service provision is associated with a more left-wing government.

${ }^{2}$ There is a number of papers that study the recent wave of populism (see e.g. Guiso et al., 2017; Guiso and Sonno, 2020; Heinisch, 2003; Kane and McCulloch, 2017; Sasso and Morelli, 2020). These papers are not concerned with the efficiency implications of populism, however, they often study determinants of this rise in attractiveness of populists. Guiso et al. (2017); Guiso and Sonno (2020) show that economic insecurity after the global financial crisis plaid an important role in the emergence of populist parties. Other papers point out mistrust in institutions and the establishment as one of the key mechanisms (Algana et al., 2017).
} 
the Republic of Georgia (Kane and McCulloch, 2017). Another channel through which the presence of populist parties could influence efficiency is the turnover of public officials. Sasso and Morelli (2020) show that the turnover of public officials is higher under populists when bureaucracy is strong. Assuming that to be an efficient bureaucrat one needs experience, a higher turnover is likely to be associated with lower efficiency. The presence of populist parties is also associated with the polarization of the electorate, which is likely to cause difficulties in finding compromise by lawmakers (Kane and McCulloch, 2017). We expect that an increase in the share of populist is linked to a decline in the efficiency of public sector.

As a third political economy variable, we study extremist parties which share some of the characteristics of populist parties. ${ }^{3}$ However, at least in the studied Czech setting of this paper, extremist parties focus on either hard-core anti-immigrant policies (right-wing extremist) or are non-reformed communist parties (left-wing extremist) rather than solely on the criticism of the establishment. Extremist politicians are likely to focus on other issues than public good provision (such as migration for the extremists from the rightwing spectrum or general issues of capitalist society for the extreme left, see e.g. Gerling and Kellermann, 2019). Irrespective of their participation in the government, the presence of extremist parties in councils, might disrupt the council meetings by adding less related topics to the agenda or distracting the attention to extremist points (Kane and McCulloch, 2017). Similarly to the populist parties, extremists are found to have had difficulties in attracting qualified public servants (Heinisch, 2003). Perhaps the closest paper to ours is a study by Ziller and Goodman (2020), which finds a negative link between efficiency and right-wing violence in Germany. The authors remain silent about the effect of the presence of extremist politicians in (regional) parliaments, though. Thus, in the case of extremist parties, we expect none or a negative association, i.e. a higher presence of extremist parties in the regional councils associated with a lower regional efficiency.

To test the propositions, we measure the global spending efficiency. Therefore, we estimate a composite indicator from the inefficiency in three main policy domains: education, healthcare, and infrastructure provision. The composite indicator is obtained from the 'Benefit of the Doubt' (BoD) model, which allows for regional heterogeneity and differences in regional preferences. The efficiency scores for each of the three policy domains are obtained from a robust non-parametric DEA model that relates regional spending per capita in each

\footnotetext{
${ }^{3}$ There is relatively broad academic literature within political science and economics on extremist political parties. It is often concerned with drivers of the support of the extremist parties. On a 140 years long dataset covering 20 advanced economies, Funke et al. (2016) find that voters are mostly attracted to the political extreme right after financial crises. Their vote share increases on average by $30 \%$ after a crisis. Friehe et al. (2020) also study voting behaviour and find a significant negative impact of the availability of West German $\mathrm{TV}$ on the share of votes for extremist parties.
} 
of the policy domains (serving as an input in the efficiency model), respectively, with the quality-adjusted outputs in the respective policy domain. Moreover, the BoD model aggregates the dimensions in the most favorable way (Melyn and Moesen, 1991) such that we do not ex ante make any (possibly discriminatory) assumption about which outcome is more important than the other. We mitigate the influence of outlying observations and regional differences by using insights from robust, conditional efficiency models (De Witte and Kortelainen, 2013; Daraio and Simar, 2007a). To obtain the significance levels and the directions of the correlations between the shares of left-wing, populist, and extremist politicians and the efficiency, we use non-parametric regressions as suggested by De Witte and Kortelainen (2013).

In this application, we focus on the Czech regions for which we have exceptionally good panel data. ${ }^{4}$ In addition, Czechia is an interesting country to this research question for the following four reasons. First, as in many other counties, ${ }^{5}$ the Czech public administration has been traditionally relatively politicized since the Velvet Revolution in 1989. This suggests that the elected politicians might have powers to influence the management of the regions. ${ }^{6}$ Second, similarly to the rest of the developed world, ${ }^{7}$ there is a number populist and extremist parties that have recently emerged in Czechia. ${ }^{8}$ Third, the party political system is fractionalized such that the political landscape is less stable, which gives rise to more opportunities to exploit the variation induced by the changes in power. ${ }^{9}$ Note that this is not unique to the Czech Republic, many political systems in Europe experience relatively high fractionalization (The World Bank, 2017). Last, the Czech republic is, in terms of perceived institutional quality, comparable to high income countries with high levels of perceived corruption such as South Korea or Italy ${ }^{10}$, which further suggests that our results

\footnotetext{
${ }^{4}$ The spending of regional governments in the Czech Republic is equivalent to about $10 \%$ of GDP (Ministry of Finance of the Czech Republic, 2020).

${ }^{5}$ Bureaucratic apparatus tends to be politicized in many southern European countries such as Italy or Spain as well as other post-communist countries in Central Eastern Europe such as Hungary or Bulgaria (Gherghina and Kopecký, 2016).

${ }^{6}$ There has been repeated criticism by the European Commission, GRECO and other international organization of the politicization of the public sector in the country. In fact, only in 2015, a public servant act - intended to depoliticize the public sector - came into power. Nevertheless even after that, many of the European Commission's recommendations remain only partially solved. For details, see https://en. frankbold.org/sites/default/files/tema/briefing-civil\_service\_act-2015-10-09\_0.pdf.

${ }^{7}$ For a more detailed discussion about the extent and the reasons of the rise of populism (see Heinisch, 2003; Sasso and Morelli, 2020).

${ }^{8}$ See, for instance, https://www.belltower.news/2019-european-parliament-election-farright-parties-in-czech-republic-84491/.

${ }^{9}$ Titl and Geys (2019); Titl et al. (2019) also exploit the changes in political landscape to study the implications of political campaign donations on the allocation of public procurement contracts.

${ }^{10}$ Czechia is ranked $38^{t h}$, South Korea $45^{t h}$ and Italy $52^{\text {nd }}$ in 2018 of the Corruption Perception Index (Transparency International, 2019).
} 
could have external validity besides Czechia.

Our findings can be summarized along the following lines. First, we find that there is an unfavorable association between the global spending efficiency and the share of councillors from left-wing political parties. The negative relationship can be contributed to a low efficiency of health provision, while left-wing councillors appear to perform well in education provision. It appears that the negative influence on the healthcare provision prevails. Second, we do not observe any significant association between the presence of populist councillors and the global spending efficiency. However, within the policy domains, we find a significant and negative relationship suggesting that the presence of populist councillors is associated with a lower efficiency of the education provision. Lastly, we do not find any clear evidence on the association between the efficiency of regional governments and the presence of extremist parties.

The remainder of the paper is structured as follows. Section 2 describes the institutional setting of the Czech regions. In the third section, we describe our empirical methodology - i.e. the fully non-parametric robust DEA model that is used to estimate the three efficiencies and the robust, conditional Benefit-of-the-Doubt model used to calculate the composite indicators for the global spending efficiency. In the fourth section, we present our data. Subsequently, we discuss the findings and conclude.

\section{Institutional setting}

We focus on regional governments in the Czech Republic. The country consists of 13 regions and the capital of Prague. In our analysis, we focus on the regions only. Prague is a hybrid between a city and a region and, for instance, the elections to the city council ${ }^{11}$ take place at the same time as for other cities, i.e. not simultaneously with the regions. Hence, Prague is excluded. The regions were devised in 1997 (Act no. 347/1997 Coll.), and started functioning in the beginning of 2000s. Economic policies including transport, infrastructure and delegated powers in education and health care are the main competencies of the regions (Hooghe et al., 2016).

The political system of the Czech regions functions as follows. Voters directly vote the members of the Regional Council (in Czech "Zastupitelstvo kraje"), which has from 45 to 65 members depending on the size of the region. The Regional Council members then elect members of the Board of Councillors ("Rada kraje") and Governor of the Region ("Hejtman") which can be considered the government and the prime ministers of the regions. The

\footnotetext{
${ }^{11}$ There is no Prague regional council only the city council.
} 
Regional Councils can be seen as parliaments - the legislative bodies of the regions. According to the law, the Boards and the Governors are accountable to the Regional Councils.

We exploit the variation in the changes in the composition of the regional parliaments. The advantage of the Czech political system is that it is relatively highly fractionalized - similarly as in other European countries such as Belgium or the Netherlands. On the central level, there are currently 9 different parties in the Chamber of Deputies of the Czech Parliament and a few other small parties in the Senate. This is also reflected in the regional politics where we count 93 different political parties and movements that ran in the period 2008-2016. ${ }^{12}$ Out of these parties and movements 55 ever won at least one seat in the regional councils. Still, most of the seats contribute to bigger parties that include traditionally big parties such as the Czech Socially Democratic Party or the Civic Democratic Party (those have been very strong especially before 2012) and newly emerged populist parties such as, for instance, ANO - a party of the current (2019) prime minister and a billionaire.

Due to these institutional characteristics, the Czech Republic provides an interesting setting. We exploit the richness in the number of parties and changes in the shares of seats these parties hold over time to study the association between the political stance of a party and the efficiency of regional governments. In Section 3.4, we describe in detail which parties we consider left-wing oriented, which populist and which extremist.

\section{$3 \quad$ Methodology}

To study how the shares of left-wing, populist and extremist parties are associated with the global spending efficiency, we proceed in three steps. First, we estimate robust, unconditional efficiency within each of the three main policy domains (i.e., education, healthcare and infrastructure) using the DEA model. Second, to measure the global spending efficiency, we use the robust Benefit-of-the-Doubt model (for a similar approach, see D'Inverno et al., 2018). This model specification is attractive for our application as it allows us to assess the performance of the regions, while we do not ex-ante make any assumption about which policy area is more important. In this estimation, we condition on regional specific characteristics and time trends. Third, we use non-parametric local linear regression of the share of conditional and non-conditional scores (see De Witte and Kortelainen, 2013) on our independent variables of interest (the share of regional councillors with particular political stance - left-wing, populist or extremist) to obtain the direction of the correlation between the global spending efficiency and the shares of of regional councillors from left-wing, populist and extremist parties, respectively. Finally, in a methodologically identical way, we

\footnotetext{
${ }^{12}$ This includes 3 elections in 2008, 2012 and 2016.
} 
also estimate, separately for each policy domain, the direction of the correlation between the share of councillors with a particular political stance and the efficiency of provision within particular policy domain. In this step, we again use conditional specification of the DEA model.

\subsection{Data Envelopment Analysis}

To calculate the efficiency of education, healthcare, and infrastructure provision, we employ a Data Envelopment Analysis (DEA) model, which is a non-parametric efficiency tool developed and introduced by Farrell (1957). It was first implemented by Charnes et al. (1978, 1981) and, in our application, it relates regional spending per capita in one of the three policy domains (as an input) with the quality-adjusted outputs in the given policy domain.

We implement the DEA input-oriented model, which aims to minimize the spending for a given level of provision. The reasoning behind this choice is that we are interested in measuring which decision making units use the least resources to provide a certain level of education services, healthcare services, and infrastructure, respectively. We adjust all outputs for the differences in quality. A detailed discussion of the variable choice and the quality adjustment is in Section 3.4.

The DEA model does not assume a functional form of the production function, which is appealing to avoid the common specification bias (Yatchew, 1998). It rather assumes that public good production technology is a characterized by transformation of a set of inputs $x \in \mathbb{R}_{+}^{p}$ into a set of outputs $y \in \mathbb{R}_{+}^{q}$ and the production set that is defined as follows (we follow notation by Cazals et al., 2002):

$$
\Psi_{D E A}=\left\{(x, y) \in \mathbb{R}_{+}^{p+q} \mid x \text { can produce } y\right\}
$$

The efficiency score for a region-year observation (characterized by input $x_{0}$ and output $\left.y_{0}\right)$ is defined as the Farrell-Debreu input-oriented efficiency score (Debreu, 1951; Farrell, 1957) by:

$$
\theta\left(x_{0}, y_{0}\right)=\inf \left\{\theta||\left(\theta x_{0}, y_{0}\right) \in \Psi_{D E A}\right\}
$$

In this input-oriented approach, we evaluate how much less input $x$ could be sufficient to produce the same level of output $y_{0}$ if the region-year observation unit at hand performed as the best observed units. In essence, we measure the distance from the frontier $\Psi_{D E A}$.

To construct this frontier, we define the smallest free disposal convex set as follows 
(Charnes et al., 1978; Fried et al., 2008):

$$
\begin{aligned}
\Psi_{D E A}=\left\{(x, y) \in \mathbb{R}_{+}^{p+q} \mid y \leq \sum_{i=1}^{n} \gamma_{i} Y_{i} ; x \geq \sum_{i=1}^{n} \gamma_{i} X_{i} \text { for }\left(\gamma_{1}, \ldots, \gamma_{n}\right)\right. \\
\left.\quad \text { such that } \sum_{i=1}^{n} \gamma_{i}=1 ; \gamma_{i} \geq 0 ; i=1, \ldots, n\right\}
\end{aligned}
$$

When the score $\theta$ from Equation (2) is equal to 1, then the observation at hand is considered efficient. A score of 0.8 can be interpreted such that the unit under-performs by $20 \%$ given the best performing units.

The specification above allows for variable returns to scale as in Banker et al. (1984). However, as argued in the survey on public good provision by Martimort et al. (2005), public good production is characterized by increasing returns to scale. Indeed, in the provision of education or healthcare, it is likely that the outputs increase by a larger proportion than the increase in inputs. ${ }^{13}$ Therefore, we adjust the constraint $\sum_{i=1}^{n} \gamma_{i}=1$ in Equation (3) to:

$$
\sum_{i=1}^{n} \gamma_{i}<1
$$

The traditional DEA model, as described in equation 1, is deterministic. As there might be outlying and atypical observations in the sample, we again follow the approach suggested by Cazals et al. (2002) and construct the order- $m$ partial frontier. The procedure is as follows. We draw a sample of size $m(<n)$ with replacement from those observations that satisfy $X_{i} \leq x_{0}$, where $\left(x_{0}, y_{0}\right)$ is the observation at hand. Repeating the re-sampling $B$ times, we compute efficiency scores for each draw. The final efficiency is then defined as the arithmetic mean of the $B$ efficiency scores calculated for each region-year observation. To set $m$, we follow Daraio and Simar (2005) and calculate the number of super-efficient observations for different values of $m$ and check for which $m$ so that the number the share of super-efficient observations. The shares appear stable for $m>50^{14}$ (see Figures OA.1, OA.2, and OA.3 in Appendix). Thus, we set $m=50$ and $B=2000$.

A possible concern could be that we compare observations that are not comparable, because they operate in a different environment. Thus, to make the assumption of homogeneity among the production functions of the units in our sample more realistic, we extend the ro-

\footnotetext{
${ }^{13}$ For a review of how to obtain qualitative information about scale economies see Kerstens and Eeckaut (1999).

${ }^{14}$ The thresholds from which the share is stable slightly differ for each of the three policy domains, however, for all of them the shares appear stable above 50. It should be noted that our results are robust to using slightly different values of $m$.
} 
bust DEA model to a conditional model that accounts for environmental factors. Ignoring the heterogeneity in the global spending efficiency of the regions could result in biased estimates (Daraio and Simar, 2005, 2007b; Simar and Wilson, 2011). Instead of drawing each observation with the same probability during re-sampling (we re-sample $m$ observations $B$ time as above), the conditional model assigns to each observation a probability such that the observations with similar observable characteristics are drawn with higher probability. The exact probabilities are determined by a Kernel function around relevant exogenous characteristics $(z)$ as follows:

$$
\text { probability }_{i}=\frac{K\left(z_{0}-Z_{i}\right)}{h} / \sum_{i=1}^{n} \frac{K\left(z_{0}-Z_{i}\right)}{h}
$$

where $\mathrm{K}($.$) denotes a Kernel function and h$ the bandwidth. We estimate the bandwidth by likelihood cross-validation method Badin et al. (2010). The final composite indicators are then obtained (as above) as a mean of $B$ calculated scores:

$$
\tilde{C} I_{m, n}(y \mid z) \sim \frac{1}{B} \sum_{b=1}^{B} \tilde{C} I_{m}^{b, z}(y)
$$

\subsection{Accounting for the influence of exogenous factors on efficiency}

To evaluate the association between the efficiency of the provision in each policy domain and the shares of different groups of political parties in the regional council, we apply a nonparametric bootstrap procedure developed by De Witte and Kortelainen (2013) and later used in, e.g., Asatryan and De Witte (2015) or D'Inverno and De Witte (2020). Specifically, we run a local-linear regression of the ratio of conditional efficiency scores and unconditional scores on exogenous variables.

$$
\frac{\tilde{\theta}_{m, n}(x, y \mid z)_{i}}{\tilde{\theta}_{m, n}(x, y)_{i}}=f\left(z_{i}\right)+\varepsilon_{i}
$$

To test significance, we employ a naive bootstrap as in (De Witte and Kortelainen, 2013). The signs from this regression can be used to determine whether a larger value of $z$ is associated with a higher or lower efficiency score (Daraio and Simar, 2005). In an inputoriented model, "an increasing regression corresponds to a unfavorable environmental factor and a decreasing regression indicates an favorable factor" (Daraio and Simar, 2007a, p.115). 


\subsection{Benefit of the Doubt model to calculate the global spending efficiency}

To assess the global spending efficiency of the Czech regions, we calculate a composite indicator using the three efficiency scores from the previous section. We do so using a fully non-parametric Benefit of the Doubt (BoD) model (for details, see Melyn and Moesen, 1991), in which the three indicators are the efficiency scores obtained from the DEA models described above (i.e., three sets of efficiency scores for education, healthcare, and infrastructure, respectively). Compared to standard composite indicators with fixed weights for the dimensions, in the $\mathrm{BoD}$ model, the weights on the dimensions are determined endogenously. This is attractive in the application at hand as it reflects that regions might have different preferences. It does not ex-ante presuppose any weights for particular policy preferences such as, for instance, that providing quality education is more important than providing infrastructure.

Formally, the $\mathrm{BoD}$ model can be stated as the following linear programming problem (Melyn and Moesen, 1991):

$$
\begin{gathered}
C I_{i}=\max \quad \sum_{r=1}^{s} y_{i, r} w_{i, r} \\
\text { s.t. } \sum_{r=1}^{s} y_{j, r} w_{i, r} \leq 1, \quad \text { for } \mathrm{j}=1, \ldots, \mathrm{n}, \\
w_{i, r} \geq 0, \quad \text { for } \mathrm{r}=1, \ldots, \mathrm{s}
\end{gathered}
$$

where $i$ represents one of $n$ regions, $C I_{i}$ stands for the composite indicator value for the particular region. For each indicator $r, y_{i, r}$ represents the measured service provision in region $i$. And $w_{i, r}$ is the set of most favorable weights for the region $i$.

In our implementation, as in the DEA model above, we extend this model by applying the order- $m$ methodology (Cazals et al., 2002), which makes the indicator robust to outliers by applying Monte Carlo simulation on the usual computation of the composite indicator. In particular, we repeatedly ( $B$ times) draw $m$ observations. To set $m$, we follow Daraio and Simar (2005) and calculate the number of super-efficient observations for different values of $m$. The share of super-efficient observations appears to be stable for $m>50$, so we set $m=50$. Subsequently, we calculate the final composite indicator as the mean of $B$ indicators obtained from the Monte Carlo simulation. 
Figure 1: The share of super-efficient observations and $m$

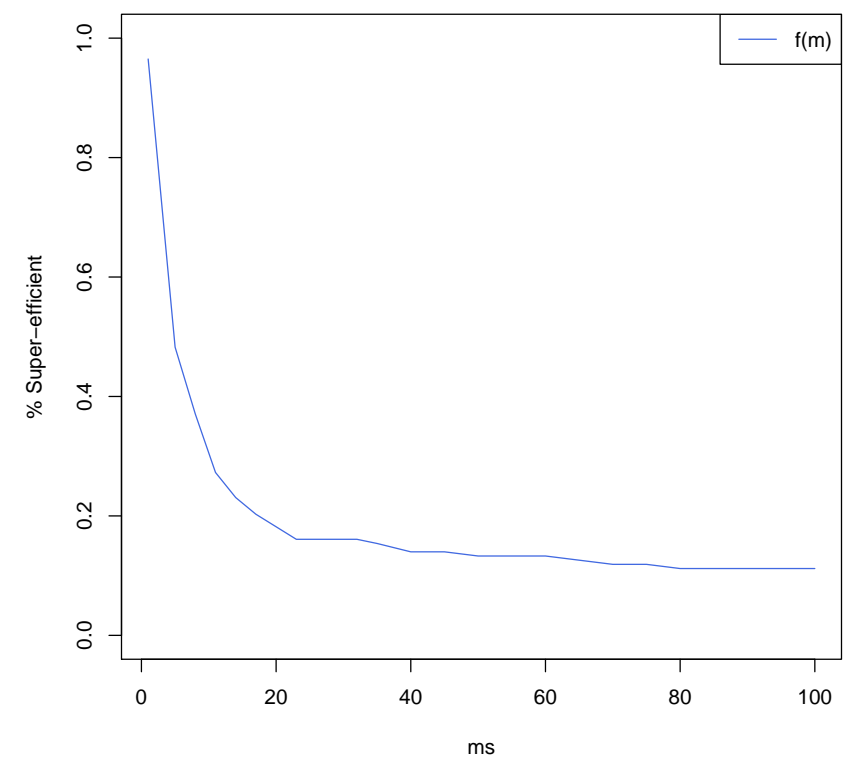

Notes: The figure shows the share of super-efficient observations for the BoD model depending on the choice of $m$.

Similarly as above, in this version of the BoD model, we might be comparing observations that operate in a different environment, which would violate the assumption of homogeneity among the production functions of the units. To overcome this issue, we implement a conditional version of the efficiency estimator (Daraio and Simar, 2005, 2007a). We proceed as above - construct a Kernel function around relevant characteristics $(z)$ and use the probabilities determined by the Kernel function to draw the observations with similar observable characteristics with higher probability. The final efficiency scores are obtained as the mean of the $B$ calculated scores. ${ }^{15}$

Finally, as with the DEA efficiency scores, we use a non-parametric bootstrap procedure developed by De Witte and Kortelainen (2013) to determine the direction and the significance of the association between the global spending efficiency and the shares of political parties with the different political stances in the regional councils.

\footnotetext{
${ }^{15}$ As before, we set set $B=2000$.
} 


\subsection{Data}

To study the efficiency of the Czech regions, we use a unique balanced region-year panel covering the period from 2007 to 2017. Given that there are 13 regions in Czechia, we have a dataset of 143 observations. To fully examine the research questions, we need data on input and outputs of the regions, data that measures the political stances of councillors, and the environmental variables.

The choice of input and output indicators within each policy domain is in line with previous literature that measures public sector efficiency on the municipal and/or regional level (see, for example, De Borger and Kerstens, 1996; Geys et al., 2010; Asatryan and De Witte, 2015). As outlined in the section on the institutional setting, the most important competencies of regions in Czechia are education, healthcare, and infrastructure. These competencies constitute more than three quarters $(76 \%)$ of the total spending of the regions. We take the per capita expenditure on each of the policy areas as input. The summary statistics on these input indicators, provided in Panel I of Table 3, show that an average region spends 8.362 thousand CZK per capita on education, 3.02 thousand CZK on infrastructure, and 0.734 thousand CZK on healthcare. The detailed expenditure data were collected from the annual accounts of the Czech regions.

For each policy domain, we take a set of output indicators. As well as for the inputs, all output indicators are in per capita terms. The summary statistics on the quality-adjusted outputs for each of the three policy domains are presented in Table 1. Regions are obliged to provide educational services, and thus, need to maintain kindergartens, primary, and secondary schools. In those schools, there are teachers, who provide classes to pupils and students. Educated pupils and students can be seen as the final outcome, nevertheless, maintaining the school buildings and keeping staff is necessary in the long-run. Therefore, similarly to Geys et al. (2010), we use the number of pupils, teachers and schools (as approximation of school buildings) for kindergartens, primary and secondary schools as measures of education output. Given that the goal is to have educated pupils and students (and not only pupils and students that "went through" the institutions), we adjust the output variables by a proxy for quality of each regional education system. ${ }^{16}$

The adjustment for quality of education outputs is done as follows. For each year, we identify the highest regional average PISA score. ${ }^{17}$ For instance in 2006, the highest average

\footnotetext{
${ }^{16}$ Note that compared to the measures of quality for the other two policy domains, the PISA scores are not updated annually but but only once in three years. We use the available PISA scores from 2006, 2009, 2012, and 2015. The scores from 2006 are used for 2007 and 2008, the scores from 2009 are also used for 2010 and 2011 and so on.

${ }^{17}$ The data are obtained from the reports of the Czech school inspection (https://www.csicr.cz/).
} 
PISA score for a Czech region was 524.8 in Vysocina region ${ }^{18}$ (for a similar approach, see Cordero et al., 2020). In line with the best practice frontier idea, subsequently, we calculate a percentage capturing to which extent a given region in a given year achieved the maximum possible PISA score within the country. Say that a fictional region with 10 secondary schools achieved on average a PISA score of 472.3 in 2006, then we will adjust (multiply) each output of this fictional region by the coefficient of $0.9 .{ }^{19}$ I.e. in our efficiency estimation, we will use the quality adjusted output indicator for the number of schools equal to 9 (10 actual secondary schools $\times$ thecoefficient0.9). Each education output is multiplied by the same region-year specific coefficient. The output indicators of the best performing region in the given year (the Vysocina region in this case) remain unchanged (multiplied by 1.0). The summary statistics on the raw output indicators (before adjustment for quality) and the quality proxies are presented in Sections A, B of Appendix, respectively. In Panel I of Table 1, we then present the quality adjusted output indicators for education. For example, the indicator "Nr. of teachers in secondary school" can be interpreted such that, per 1000 inhabitants, there are on average 3.8 teachers in the quality of the region with the best educational system across the Czech regions and years 2007 - 2017.

\footnotetext{
${ }^{18}$ Prague, which usually performs the best, is excluded throughout the paper as it does constitute a region in the same way as other regions. For instance, elections for Prague city council (it does not have a regional council) takes place in different time.

$19 \frac{472.3}{524.8} \approx 0.9$
} 
Table 1: Quality-adjusted outputs indicators in 3 policy domains

\begin{tabular}{|c|c|c|c|c|c|c|c|}
\hline All variables per 1000 inhabitants & $\mathrm{N}$ & Mean & St. Dev. & Min & $\operatorname{Pctl}(25)$ & $\operatorname{Pctl}(75)$ & Max \\
\hline \multicolumn{8}{|l|}{ Panel I: Education output indicators } \\
\hline Nr. of kindergartens & 143 & 0.479 & 0.075 & 0.342 & 0.412 & 0.536 & 0.608 \\
\hline Nr. of teachers in kindergartens & 143 & 2.417 & 0.282 & 1.874 & 2.194 & 2.670 & 2.910 \\
\hline Nr. of children in kindergartens & 143 & 30.717 & 3.327 & 24.539 & 28.144 & 33.566 & 36.749 \\
\hline Nr. of primary schools & 143 & 0.407 & 0.059 & 0.300 & 0.359 & 0.453 & 0.517 \\
\hline Nr. of teachers in primary schools & 143 & 5.569 & 0.336 & 4.637 & 5.371 & 5.776 & 6.436 \\
\hline Nr. of students in primary schools & 143 & 77.788 & 5.198 & 64.911 & 74.102 & 81.574 & 90.440 \\
\hline Nr. of secondary schools & 143 & 0.124 & 0.017 & 0.092 & 0.112 & 0.141 & 0.171 \\
\hline Nr. of teachers in secondary schools & 143 & 3.871 & 0.501 & 2.569 & 3.553 & 4.283 & 4.862 \\
\hline Nr. of students in secondary schools & 143 & 44.829 & 6.671 & 28.352 & 39.984 & 49.864 & 58.749 \\
\hline \multicolumn{8}{|l|}{ Panel II: Healthcare output indicators } \\
\hline Nr. of doctors & 143 & 3.566 & 0.517 & 2.279 & 3.238 & 3.855 & 5.072 \\
\hline Nr. of hospitals & 143 & 0.015 & 0.003 & 0.011 & 0.013 & 0.017 & 0.021 \\
\hline Nr. of beds hospitals & 143 & 4.778 & 0.608 & 3.406 & 4.332 & 5.116 & 6.730 \\
\hline Nr. of spec. medical institutes & 143 & 0.013 & 0.005 & 0.006 & 0.009 & 0.016 & 0.025 \\
\hline Nr. of beds in medical institutes & 143 & 1.788 & 0.840 & 0.461 & 1.189 & 2.305 & 4.324 \\
\hline \multicolumn{8}{|c|}{ Panel III: Infrastructure output indicators } \\
\hline Roads class 2 in $\mathrm{kms}$ & 143 & 1.034 & 0.863 & 0.081 & 0.408 & 1.168 & 3.186 \\
\hline Roads class 3 in $\mathrm{kms}$ & 143 & 2.356 & 1.711 & 0.191 & 0.922 & 3.109 & 5.999 \\
\hline Length railways in $\mathrm{kms}$ & 143 & 0.623 & 0.394 & 0.068 & 0.316 & 0.934 & 1.542 \\
\hline
\end{tabular}

Notes: Dataset covers years 2007 to 2017. Education output indicators are adjusted for quality using average PISA scores in each region. Healthcare output indicators are adjusted using the number of deaths caused by cancer or heart attack per capita in each region-year as proxy for quality. Infrastructure output indicators are adjusted using the number of accidents per capita in each region-year. Source: Authors' elaboration based on Czech Statistical Office. 
Regional governments also run hospitals and other medical institutes. To account for differences in sizes of the hospitals and medical institutes, we include the number of beds in these institutions and the number of doctors among the healthcare output indicators (for a similar choice of outputs, see Asatryan and De Witte, 2015). The overall goal of the healthcare system is to have a healthy population that lives long (and have high-quality lives) and not only many hospitals with doctors employed in them. Therefore, we use the number of deaths caused by either cancer or heart attack per capita in each region-year combination as measures of the quality of the healthcare system and adjust all the output variables using this quality measure. ${ }^{20}$ Naturally, the number of deaths caused by either cancer or heart attack per capita is an inverse measure of quality. Thus, we proceed in the following way. For each year, we identify the observation with lowest number of deaths (let us assume $\min \left\{\right.$ deat $\left._{2007}\right\}=0.002$ ). Let us take again a fictional region-year observation $i$ with the number of deaths caused by cancer and heart attacks equal to 0.003 (death $\left.h_{i, 2007}\right)$. Then we will adjust each healthcare output of this region-year observation by the following fraction:

$$
\frac{1}{\frac{\text { death } h_{i, 2007}}{\min \left\{\text { death }_{2007}\right\}}}=\frac{1}{\frac{0.003}{0.002}} \approx 0.667
$$

As in the case of education, each output indicator for healthcare is multiplied by the same region-year specific coefficient.

Finally, regions are maintaining roads of class 2 and 3 (which are all roads except highways, because these are maintained by the central government; Act No. 13/1997 Coll. on Roads), and order rail transport from railway companies for the provision of local and regional transport services. Therefore, we include the length of roads of class 2 and 3, and the length of railways. Analogical to healthcare outputs, we take into account how well the infrastructure is maintained by adjusting the outputs by the number of road accidents per citizen. $^{21}$

It should be noted that these measures have their limitations as not all hospitals or schools are run by the regions. However, we believe that they constitute a good approximation of total production and provision of public good. Specifically, there is only about $5 \%$ private primary schools ${ }^{22}$, about $70 \%$ of secondary schools are region-run and approximately two thirds of healthcare facilities are directly or indirectly owned by the regions. The regions are in charge of taking care of all roads of class 2 and 3. Finally, they buy rail transport from private providers.

\footnotetext{
${ }^{20}$ The data come from the Czech Statistical Office.

${ }^{21}$ The data are obtained from the Czech Statistical Office.

${ }^{22}$ According to Czech Statistical Office (2015), there are 143 private primary schools and 43 church-run primary schools out of 4,106 primary schools the country.
} 
Summary statistics, provided in Panel II of Table 3, show that the mean efficiency scores exhibit relatively high variation. This is because these scores are unconditional, i.e., regions that may substantially differ across dimensions such as the shares of youth and elderly, are compared to each other. In the subsequent analysis, we employ the conditional efficiency model which includes environmental variables to control for these characteristics. We use the revenue of regional governments per capita, ${ }^{23}$ the share of youth (people below 15 years old) and the share of elderly (people above 65 years old), which reflect the income (and, hence, the taxable basis) and the population structure. The seminal work by Poterba (1997) shows the role of demographic structure, while Jäger and Schmidt (2016) point to the differences in public investments if population structures are changing. In their review of the literature, Narbón-Perpiñá and De Witte (2018a,b) show that there is an extensive body of literature using population structure, income and various proxies of income as environmental variables (e.g., Asatryan and De Witte, 2015; Geys et al., 2010).

We manually collect information about all regional councillors and their political affiliation in the period 2007 to 2017. There were 3 elections in the period: 2008, 2012 and 2016. In each election voters choose 675 members of the councils $(45,55$ or 65 members per each regional council). To calculate the shares of councillors from left-wing, populist and extremist parties, we need to label political parties according whether they belong to one of the groups.

First, defining left-wing parties is relatively straightforward. There are traditionally two parties - the Czech Social Democratic Party (ČSSD) and the (reformed) Communist Party of Bohemia and Moravia (KSČM). These parties are generally considered as left-wing parties and the members of the parties also proclaim themselves to be left-wing politicians (this is not the case for politicians of other parties that sometimes suggest left-wing policies). In the European Parliament, they are members of the Party of European Socialists and the European United Left-Nordic Green Left, respectively - which are both standard left-wing political groups with a clear left-wing ideological stance.

Second, we define populists similarly as in Havlík and Voda (2018), i.e. parties that are non-ideological and present themselves as an "anti-political alternative to the established parties" (Havlík and Voda, 2018, p. 162). In the Czech setting, this corresponds to two parties: 'Public Affairs' (Věci veřejné) and 'Action of Dissatisfied Citizens' (Akce nespokojených občanů, ANO). The first does not exist anymore, but was present in Topolanek's government till 2009, after which the party has fallen apart due to a wave of scandals. The latter is established by a Czech billionaire, Andrej Babis, in 2011 and is currently, in 2019, the main party in the coalition government. Since 2016, the party has been voted in power

\footnotetext{
${ }^{23}$ Note that we adjust these revenues for inflation.
} 
in some regional councils. In some of them, such as the Central Bohemian region, the party has held a majority in the Regional Board as well.

Third, extremist parties include both left-wing and right-wing extremists. In the Czech regions, this corresponds to the parties 'Freedom and Direct Democracy' (SPD), the 'Dawn of Direct Democracy' (Úsvit) and the 'Communist Party of Czechoslovakia' (KSČ). The fist two parties are hard-core right-wing parties with strong anti-immigrant statements, while the last party is a strong left-wing (non-reformed) communist party. An overview of the parties is give in Table 2. In Figure 2, we then plot the shares of councillors of each type of political party over time (note that this is an average for all 13 regions). It is clear that left wing parties have held a relatively large share of seats in the councils over the whole studied period of time. This share peaked at slightly above $40 \%$ and gradually declined over time to approximately 30\%. The populist parties gained many seats in 2016 . This is linked to the raise of the party 'ANO'. Before that, they held only a very limited share of council seats between 2008 and 2012. Finally, the extremist parties have gradually gained more and more seats and then they lost practically all their seats in 2016.

Table 2: The Czech political parties and their political stance

\begin{tabular}{ll}
\hline & Parties \\
\hline Left-wing & KSCM, CSSD \\
Populist & ANO, Věci veřjejné \\
Extremist & SPD, Úsvit, KSČ \\
\hline
\end{tabular}

Source: Authors

Having labeled the political parties, we can calculate the shares of councillors affiliated with the respective parties. To do so, we collect information about all regional councillors in the period from 2007 to 2017. The resulting shares of left-wing, populist and extremist councillors are presented in Table 3. In some regions, there are no populist parties while in other regions the share of populist parties amounts to 0.36 . We observe a similar variability for the share of extremist parties, which varies between 0 and 0.47 . 
Table 3: Summary statistics input, output and control variables

\begin{tabular}{lccccccc}
\hline \hline Statistic & $\mathrm{N}$ & Mean & St. Dev. & Min & Pctl(25) & Pctl(75) & Max \\
\hline Panel I: Input & & & & & & & \\
\hline Education expenditure & 143 & 8.362 & 2.426 & 0.357 & 8.500 & 9.465 & 11.243 \\
Healthcare expenditure & 143 & 0.734 & 0.605 & 0.122 & 0.541 & 0.820 & 7.196 \\
Infrastructure expenditure & 143 & 3.020 & 0.816 & 0.904 & 2.516 & 3.574 & 5.748 \\
\hline Panel II: Output & & & & & & & \\
\hline Efficiency of education provision & 143 & 0.125 & 0.237 & 0.042 & 0.052 & 0.063 & 1.000 \\
Efficiency of healthcare provision & 143 & 0.362 & 0.116 & 0.037 & 0.302 & 0.399 & 1.000 \\
Efficiency of infrastructure provision & 143 & 0.560 & 0.197 & 0.299 & 0.398 & 0.693 & 1.246 \\
\hline Panel III: Political stance measures & & & & & & & \\
\hline Share of left parties & 143 & 0.365 & 0.146 & 0.000 & 0.300 & 0.422 & 0.677 \\
Share of populist parties & 143 & 0.049 & 0.102 & 0 & 0 & 0 & 0.364 \\
Share of extremist parties & 143 & 0.103 & 0.151 & 0 & 0 & 0.2 & 0.472 \\
\hline Panel IV: Environmental variables & & & & & & & \\
\hline Revenue per capita & 143 & 16.840 & 1.998 & 13.190 & 15.508 & 18.199 & 22.576 \\
Share of youth & 143 & 14.945 & 0.656 & 13.834 & 14.527 & 15.293 & 17.497 \\
Share of elderly & 143 & 16.795 & 1.811 & 13.005 & 15.253 & 18.289 & 20.726 \\
\hline
\end{tabular}

Notes: Education, healthcare, and infrastructure expenditure, respectively is expenditure of the region in thousands of CZK per capita (23 CZK is equivalent to approximately $1 \$$ ) in given policy area. Outputs are calculated as efficiency scores using a robust and conditional DEA model (see Section 3). The share of left-wing parties equals the number of left-wing regional councillors divided by the total number of councillors. The share of populist parties equals the number of regional councillors from populist parties divided by the total number of councillors. The share of extreme parties equals the number of regional councillors from extremists parties divided by the total number of councillors. Revenue per capita is thousand of CZK. Share of youth and elderly are the percentage shares of people below 15 and above 65, respectively. 
Figure 2: The average shares of left-wing, populist and extremist parties over time

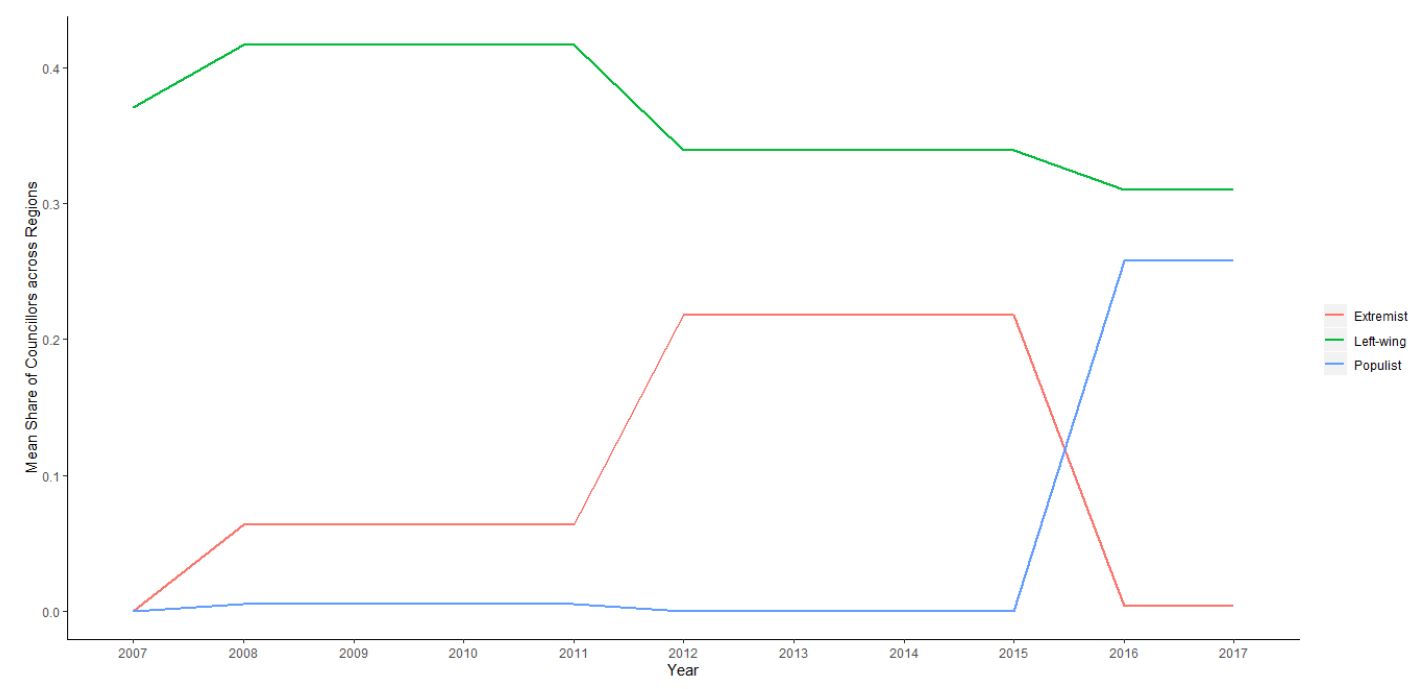

Notes: The figure depicts average shares of left-wing, populist and extremist parties over time.

\section{Findings}

In presenting our findings, we proceed in two steps. First, we present the findings on the association between the shares of councillors from the three different types of political parties and the global spending efficiency, and second, we present the findings on these associations separately for each of the three main policy domains.

\subsection{The global spending efficiency}

To analyse the relationship between the global spending efficiency and the shares of left-wing, populist, and extremist councillors, we present three sets of results - one set for each policy domain. The findings are presented in Tables 4, 5, 6, respectively. For each proposition, we estimate the unconditional model and 4 conditional models (where we gradually add more controls). ${ }^{24}$ First, we present the summary statistics on the unconditional efficiency scores (Column (1) in Tables 4, 5, 6). Second, we run a simple conditional model with only the variable of interest as environmental variable and test whether there is significant association (Columns (2)). Third, we add year time trend to control for possibly spurious results (i.e.,

\footnotetext{
${ }^{24}$ Following Daraio et al. (2015), we test whether the separability condition is satisfied to understand whether conditional estimation is necessary. We reject the null hypothesis of means of unconditional and conditional efficiency scores being statistically equal in each of the main specifications, this suggests that conditional estimation is necessary.
} 
Figure 3 suggests downward trend in the efficiency; see Columns (3)). Given that we run a non-parametric regression, the added trend is flexible and, hence, is not restricted to a linear trend. To keep the number of independent variables lower, and to avoid potential overfitting of the model, we opt to use this simpler yet flexible time trend rather than a set of 10 additional dummy variables for each year. Fourth, we run a model with control variables for regional characteristics - revenue per capita, the shares of youth and elderly (see Columns (4), the choice of the variables follow Asatryan and De Witte, 2015). Fifth, we combine the third and the fourth model to obtain a model where we control for both the time trend and the regional characteristics (Columns (5)).

Before turning to the results of the conditional efficiency estimations, we plot the unconditional robust BoD scores for all regions over time in Figure 3. There seems to be a downward trend with exception of some regions, which could make our results spurious. First, we should note that this cannot be caused by an increase in prices over time which would boost input but the output might stay the same, which would end up in a decline in the efficiency scores over time. To avoid this scenario, we adjusted our inputs for inflation. Second, the slight visual downward trend persists even after accounting for inflation. Thus, our main specification (in Columns (5)) includes a time trend. Finally, we suggest that this trend could be attributed to the well-known phenomenon of budget maximizing bureaucrats (see Niskanen, 1968, who argues that bureaus maximize budgets in order to increase their own importance and prestige $)^{25}$. Our efficiency scores suggest this latter pattern - inputs grow faster than outputs. In Figure 4, we depict the expenditures on education, healthcare, and infrastructure over and see that the expenditure has indeed increased especially in education. This growth roughly corresponds to the decline of efficiency (see Figure 3). After 2014, there seems to be a change in the trends, which is also visible in both figures.

An alternative explanation of the overall decline in the average efficiency score could be that new outputs emerged over time and we do no take them into account. Although we cannot completely rule out this possibility, competencies of the Czech regions are regulated by law and did not significantly change over time. For instance, a region cannot decide to stop funding schools or hospitals. They have freedom to choose how they invest and to set the precise investments, giving rise to differences in inefficiency, but they cannot simply stop funding schools.

\footnotetext{
${ }^{25}$ For similar arguments about fast growth of the public sector expenditure, see also Wagner (1890).
} 
Figure 3: The global spending efficiency as measured by the BoD model over time

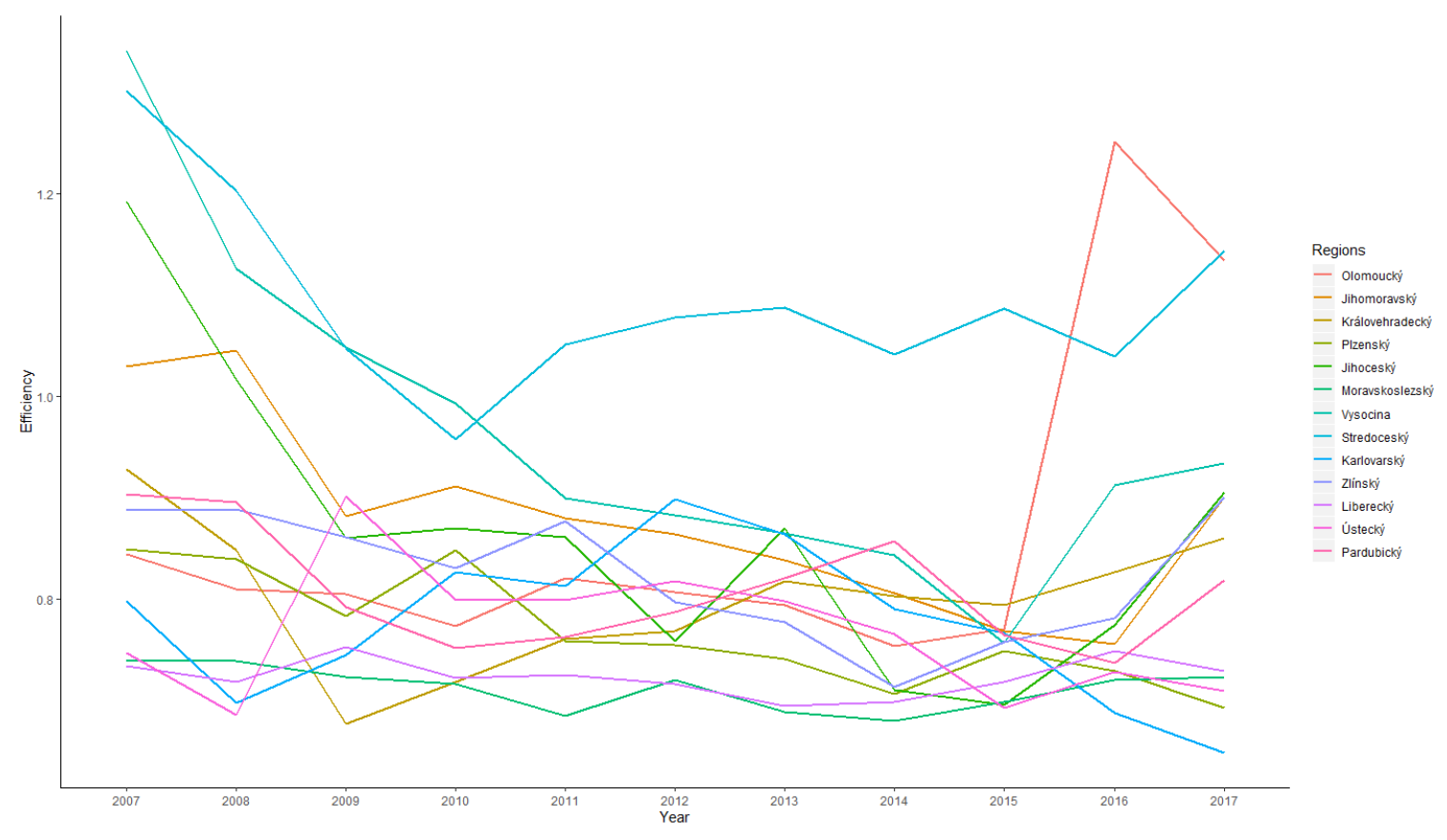

Notes: This figure depicts the global spending efficiency as measured by the $\mathrm{BoD}$ model applied on the unconditional robust DEA efficiency estimations for each of the 13 regions over time (from 2007 to 2017). 
Figure 4: The yearly regional expenditure on education, healthcare, and infrastructure over time
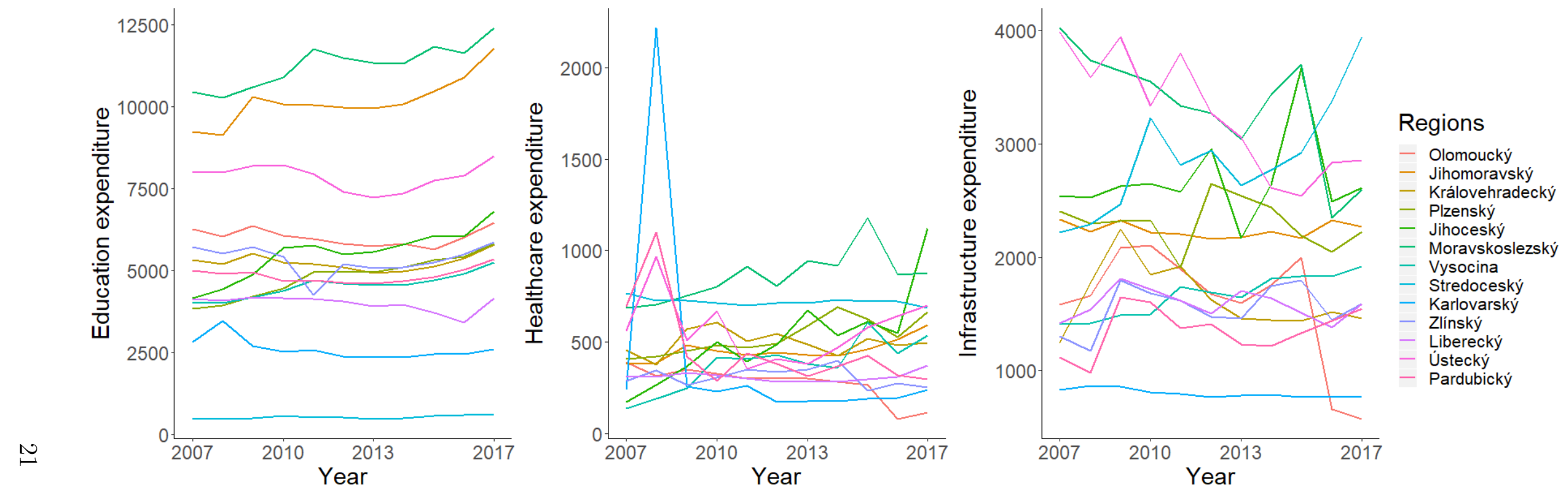

Notes: This figure depicts the regional expenditure on education, healthcare, and infrastructure adjusted for inflation (from 2007 to 2017$)$. Source: Authors' elaboration based on annual accounts of the Czech regions. 


\subsubsection{Left-wing Parties}

Our first set of results suggests that there is an unfavorable association between the global spending efficiency and the share of councillors from the left-wing political parties (Table 4). The association is statistically significant across specifications, i.e., also after accounting for region specific characteristics and the flexible time trend (Column (5)). The previous literature provides rather mixed results on this association - although De Witte and Geys (2011); D'Inverno and De Witte (2020) find that the right-wing governments are associated with lower efficiency of public good provision and service provision, respectively, Asatryan and De Witte (2015) find a statistically insignificant association that changes direction based on the specification. In contrast to this literature, our results appear more clear-cut and strongly suggest a negative relationship between the presence of left-wing councillors and the global spending efficiency.

Table 4: Correlation between the share of left-wing parties and the regional efficiency scores

\begin{tabular}{llllll}
\hline Variable & $(1)$ & $(2)$ & $(3)$ & $(4)$ & $(5)$ \\
\hline Mean eff. score & 0.840 & 0.697 & 0.704 & 0.696 & 0.686 \\
SD eff. score & 0.134 & 0.223 & 0.254 & 0.200 & 0.239 \\
Min score & 0.635 & 0.413 & 0.409 & 0.429 & 0.409 \\
Max score & 1.321 & 1.515 & 1.558 & 1.518 & 1.548 \\
Observations & 143 & 143 & 143 & 143 & 143 \\
& & & & & \\
Share of Left & - & Unfavorable*** & Unfavorable*** & Unfavorable* & Unfavorable*** \\
Year time trend & NO & NO & YES & NO & YES \\
Regional controls & NO & NO & NO & YES & YES \\
\hline
\end{tabular}

Notes: The table shows the results from a set of unconditional and conditional DEA models. Share of Left is defined as the share of left-wing regional councillors on all councillors in region $i$ and year $t$. Year time trend is a continuous variable across the years in our sample. Region controls include the revenue of regional governments per capita, the share of youth, and the share of elderly. ${ }^{* * *} \mathrm{p}<0.01,{ }^{* *} \mathrm{p}<0.05,{ }^{*} \mathrm{p}<0.1$

\subsubsection{Populism}

Populist parties throughout the world generally claim that they will solve the issues of 'the corrupt establishment' and will lead the governments in a managerial, efficient way. This would suggest a positive effect on the efficiency of (regional) governments. However, we find that the presence of populist parties in regional parliaments (and governments) is associated statistically significantly with a higher level of global spending efficiency only when time trends or region specific characteristics are not taken into account (i.e. only in Column (2) 
of Table 5). In all other specifications (see Columns (3), (4), and (5)), this relationship is consistently insignificant. Even though there is no significant relationship overall, the may be a decline and an increase of provision in other specific policy domains, which then equalize the overall relationship. Therefore, we decompose the overall effect in the following section into the effects on the three separate policy domains.

Table 5: Correlation between the share of populist parties and the regional efficiency scores

\begin{tabular}{llllll}
\hline Variable & $(1)$ & $(2)$ & $(3)$ & $(4)$ & $(5)$ \\
\hline Mean eff. score & 0.840 & 0.683 & 0.836 & 0.696 & 0.776 \\
SD eff. score & 0.134 & 0.216 & 0.626 & 0.222 & 0.464 \\
Min score & 0.635 & 0.404 & 0.468 & 0.432 & 0.435 \\
Max score & 1.321 & 1.506 & 3.445 & 1.530 & 2.777 \\
Observations & 143 & 143 & 143 & 143 & 143 \\
& & & & & \\
Share of Populist & - & Favourable*** & Favourable & Favourable & Favourable \\
Year time trend & NO & NO & YES & NO & YES \\
Regional controls & NO & NO & NO & YES & YES \\
\hline
\end{tabular}

Notes: The table shows the results from a set of unconditional and conditional DEA models. Share of Populist is defined as the share of regional councillors from populist political parties on all councillors in region $i$ and year $t$. Year time trend is a continuous variable across the years in our sample. Region controls include the revenue of regional governments per capita, the share of youth, and the share of elderly. ${ }^{* * *} \mathrm{p}<0.01,{ }^{* *} \mathrm{p}<0.05,{ }^{*} \mathrm{p}<0.1$

\subsubsection{Extremist Parties}

Lastly, the association between the global spending efficiency and the share of councillors from extremist parties appears ambiguous (see Table 6). In the specifications where a time trend is included, the share of extremist parties correlates negatively with the global spending efficiency, contrasting to the specifications without a time trend. We contribute this ambiguous finding to relatively small shares of extremist councillors or even no extremist councillors present in the councils across the majority of the studied period. The non-existence of a clear relationship between the efficiency and the share of councillors from extremist parties can also be explained by the fact that parties are often ignored by standard democratic parties (note that this is not the case for the Czech populist parties as the main one appeared in multiple regional governments and is also the strongest one in the central government). 
Table 6: Correlation between the share of extremist parties and the regional efficiency scores

\begin{tabular}{llllll}
\hline Variable & $(1)$ & $(2)$ & $(3)$ & $(4)$ & $(5)$ \\
\hline Mean eff. score & 0.840 & 0.631 & 0.679 & 0.629 & 0.665 \\
SD eff. score & 0.134 & 0.240 & 0.343 & 0.230 & 0.285 \\
Min score & 0.635 & 0.361 & 0.387 & 0.375 & 0.378 \\
Max score & 1.321 & 1.490 & 2.022 & 1.431 & 1.721 \\
Observations & 143 & 143 & 143 & 143 & 143 \\
& & & & & \\
Share of Extremist & - & Unfavourable* & Favourable*** & Unfavourable** & Favourable*** \\
Year time trend & NO & NO & YES & NO & YES \\
Regional controls & NO & NO & NO & YES & YES \\
\hline
\end{tabular}

Notes: The table shows the results from a set of unconditional and conditional DEA models. Share of Extremist is defined as the share of regional councillors from extremist parties on all councillors in region $i$ and year $t$. Year time trend is a continuous variable across the years in our sample. Region controls include the revenue of regional governments per capita, the share of youth, and the share of elderly. *** $\mathrm{p}<0.01,{ }^{* *} \mathrm{p}<0.05,{ }^{*} \mathrm{p}<0.1$

\subsection{Policy domains}

To understand which policy domains drive the findings presented in the previous section, we run a set non-parametric bootstrap estimations (as suggested in De Witte and Kortelainen, 2013)) on the DEA efficiency scores for each policy domain. ${ }^{26}$ These efficiency estimations relate the expenditure in the given domain with the quality adjusted outputs in the given domain.

\subsubsection{Education}

Politicians with different ideological leaning might be interested and skilled in higher education provision. For instance, left lining politicians are expected to prefer policies leading to more egalitarian societies (Geys and Revelli, 2009). Education could be one of such policy tools. This is also in line with previous findings of De Witte and Geys (2011) who study the efficiency of public good provision by the Flemish public libraries and find that left-wing councils are associated with a statistically significantly higher level of public good provision efficiency.

Populist parties appear to attract less managerially skilled public servants and the turnover of public officials is shown to be higher under populists (Kane and McCulloch, 2017; Sasso

\footnotetext{
${ }^{26}$ More precisely, the dependent variable is a ratio of conditional to unconditional efficiency score.
} 
and Morelli, 2020). Education provision (and other policy domains) may be demanding in terms of skilled public servants, and thus, one might expect a negative association of the share of councillors from populist parties on all councillors with the efficiency of education provision.

In Table 7, we present our findings regarding the education provision. We choose to present only the most saturated specification, i.e., the specification with a time trend and regional characteristics controls (the same as in Column (5) in the previous section). We find that, on the one hand, a higher presence of left-wing councillors is statistically significantly associated with a higher efficiency of education provision. And on the other hand, a higher share of populist councillors in regional councils is associated with a significantly lower education provision. Both these findings are in line with our research hypotheses.

Table 7: Correlation between the share of left-wing, populist, and extremist parties and the regional efficiency of education provision

\begin{tabular}{llll}
\hline Variable & $(1)$ & $(2)$ & $(3)$ \\
\hline & & & \\
Mean eff. score & 0.958 & 0.958 & 0.956 \\
SD eff. score & 0.056 & 0.055 & 0.055 \\
Min score & 0.841 & 0.837 & 0.838 \\
Max score & 1.107 & 1.094 & 1.084 \\
Observations & 143 & 143 & 143 \\
& & & \\
Share of Left-wing & Favourable*** & - & - \\
Share of Populist & - & Unfavourable*** & - \\
Share of Extremist & - & - & Favourable \\
Year time trend & YES & YES & YES \\
Regional controls & YES & YES & YES \\
\hline
\end{tabular}

Notes: The table shows the results from a set of conditional DEA models. Share of Left, Share of Populist, and Share of Extremist are defined as the shares of left-wing, populist, and extremist regional councillors on all councillors in region $i$ and year $t$, respectively. Year time trend is a continuous variable across the years in our sample. Region controls include the revenue of regional governments per capita, the share of youth, and the share of elderly. ${ }^{* * *} \mathrm{p}<0.01,{ }^{* *} \mathrm{p}<0.05,{ }^{*} \mathrm{p}<0.1$

\subsubsection{Healthcare}

Similarly as with education provision, ideological stance and managerial abilities of councillors may be related to the efficiency of healthcare provision. For instance, left-wing politicians may be expected to provide healthcare to every citizen with perhaps less regard to the quality of healthcare. Populist and especially extremist politicians are likely be less interested in 
health provision as this is not their main policy goal.

Our findings are presented in Table 8. The share of left-wing councillors is significantly associated a lower efficiency of healthcare provision. This helps us to explain the negative association of the left-wing councillors with the global spending efficiency observed in Table 4 and suggests that the overall negative association is driven by the efficiency of the healthcare provision rather the education provision. The shares of councillors from populist and extremist parties are not significantly associated with the healthcare provision efficiency.

Table 8: Correlation between the share of left-wing, populist, and extremist parties and the regional efficiency of healthcare provision

\begin{tabular}{llll}
\hline Variable & $(1)$ & $(2)$ & $(3)$ \\
\hline & & & \\
Mean eff. score & 0.932 & 0.931 & 0.939 \\
SD eff. score & 0.079 & 0.079 & 0.079 \\
Min score & 0.726 & 0.727 & 0.729 \\
Max score & 1.074 & 1.077 & 1.076 \\
Observations & 143 & 143 & 143 \\
& & & \\
Share of Left-wing & Unfavourable*** & - & - \\
Share of Populist & - & Favourable & - \\
Share of Extremist & - & - & Favourable \\
Year time trend & YES & YES & YES \\
Regional controls & YES & YES & YES \\
\hline
\end{tabular}

Notes: The table shows the results from a set of conditional DEA models. Share of Left, Share of Populist, and Share of Extremist are defined as the shares of left-wing, populist, and extremist regional councillors on all councillors in region $i$ and year $t$, respectively. Year time trend is a continuous variable across the years in our sample. Region controls include the revenue of regional governments per capita, the share of youth, and the share of elderly. ${ }^{* * *} \mathrm{p}<0.01,{ }^{* *} \mathrm{p}<0.05,{ }^{*} \mathrm{p}<0.1$

\subsubsection{Infrastructure}

Finally, we study the relationship between the share of left-wing, populist, and extremist regional councillors on all councillors with the efficiency of public infrastructure provision. The findings are inconclusive for all political stances (see Table 9). This may be surprising as voters appear to often find the issue important and they may face and see issues in infrastructure every day. However, this could also be the reason why all politicians, no matter their ideology would care about infrastructure, and would rely on public officers to actually implement the policies. The results might also be driven by the small marginal impact of additional infrastructure, and political agents focusing on symbols (and potentially 
white elephants) rather than on overall infrastructure provision.

Table 9: Correlation between the share of left-wing, populist, and extremist parties and the regional efficiency of infrastructure provision

\begin{tabular}{llll}
\hline Variable & $(1)$ & $(2)$ & $(3)$ \\
\hline & & & \\
Mean eff. score & 0.448 & 0.444 & 0.444 \\
SD eff. score & 0.295 & 0.294 & 0.293 \\
Min score & 0.045 & 0.045 & 0.045 \\
Max score & 1.049 & 1.057 & 1.045 \\
Observations & 143 & 143 & 143 \\
& & & \\
Share of Left-wing & Favourable & - & - \\
Share of Populist & - & Favourable & - \\
Share of Extremist & - & - & Favourable \\
Year time trend & YES & YES & YES \\
Regional controls & YES & YES & YES \\
\hline
\end{tabular}

Notes: The table shows the results from a set of conditional DEA models. Share of Left, Share of Populist, and Share of Extremist are defined as the shares of left-wing, populist, and extremist regional councillors on all councillors in region $i$ and year $t$, respectively. Year time trend is a continuous variable across the years in our sample. Region controls include the revenue of regional governments per capita, the share of youth, and the share of elderly. ${ }^{* * *} \mathrm{p}<0.01,{ }^{* *} \mathrm{p}<0.05,{ }^{*} \mathrm{p}<0.1$

\section{Conclusion}

This paper examines the association between the global spending efficiency of regions and the share of regional councillors from left-wing, populist and extremist parties. On a rich and unique panel dataset of Czech regional governments in the period between 2007 and 2017, we employ a fully non-parametric and conditional efficiency model to obtain the efficiency of public good provision in each of the three main policy domains separately (i.e. education, healthcare, and infrastructure), and subsequently, we evaluate the global regional spending efficiency. Finally, we examine the statistical association between the efficiency scores for each policy domain as well as the global spending efficiency and the shares of differently politically affiliated members of the Czech regional councils. To strengthen our inference, we exploit the richness of our data and account for region specific characteristics and time trends.

We present three sets of findings regarding the global spending efficiency - the association between the global spending efficiency and the share of left-wing, populist, and extremist 
regional council members. First, we find evidence that the share of left-wing members in the regional councils is negatively associated with the global spending efficiency. The relation persists even after accounting for regional characteristics and a time trend. The previous literature provided rather mixed results (see e.g. De Witte and Geys, 2011; Asatryan and De Witte, 2015). Our findings are much more clear-cut and the subsequent analysis of the efficiency of separate policy domains reveals that this decline can be contributed to a low efficiency of the health provision (while left-wing councillors appear to perform well in education provision).

Second, we do not find a clear evidence on the association between the presence of populist parties in regional parliaments (and governments) and the global spending efficiency. This relationship is consistently insignificant across our main specifications. However, when we analyse the efficiency of education provision separately, we find a significant and negative relationship suggesting that the presence of populist councillors is associated with a lower efficiency of the education provision. This might be explained by different policy preferences, but also by the previous literature that suggest that populist parties tend to attract less experienced and skilled bureaucrats in foreign policy (see Kane and McCulloch, 2017), and education may be more managerial intensive than other policy domains.

Third, we do not find any clear evidence on the association between neither the global regional spending efficiency nor the efficiency of provision in the three main policy domains and the presence of extremist parties. This is likely to be explained by two facts: (i) extremist parties are often isolated from the 'standard' democratic parties and do not participate in governments and (ii) the share of councillors from such parties remains relatively low throughout the studied period.

A limitation to our approach is that we cannot fully distinguish between private and public outputs as some of the schools and hospitals are private. This could be overcome in the future research, if more detailed data on all healthcare and education providers become available. 


\section{References}

Algana, Y., Guriev, S., Papaioannou, E., and Passari, E. (2017). The european trust crisis and the rise of populism. Brookings Papers on Economic Activity, pages 309-382.

Asatryan, Z. and De Witte, K. (2015). Direct democracy and local government efficiency. European Journal of Political Economy, 39:58-66.

Badin, L., Daraio, C., and Simar, L. (2010). Optimal bandwidth selection for conditional efficiency measures: A data-driven approach. European Journal of Operational Research, 201(2):633-640.

Banker, R. D., Charnes, A., and Cooper, W. W. (1984). Some models for estimating technical and scale inefficiencies in data envelopment analysis. Management Science, 30(9):10781092.

Cazals, C., Florens, J.-P., and Simar, L. (2002). Nonparametric frontier estimation: a robust approach. Journal of Econometrics, 106(1):1-25.

Charnes, A., Cooper, W., and Rhodes, E. (1978). Measuring the efficiency of decision making units. European Journal of Operational Research, 2(6):429 - 444.

Charnes, A., Cooper, W. W., and Rhodes, E. (1981). Evaluating program and managerial efficiency: An application of data envelopment analysis to program follow through. Management Science, 27(6):668-697.

Cordero, J. M., Polo, C., and Simancas, R. (2020). Assessing the efficiency of secondary schools: Evidence from oecd countries participating in pisa 2015. Socio-Economic Planning Sciences, page 100927.

Cusack, T. R. (1997). Partisan politics and public finance: Changes in public spending in the industrialized democracies, 1955-1989. Public Choice, 91(3-4):375-395.

Czech Statistical Office (2015). Školy a školská zařízení v České republice.

Daraio, C. and Simar, L. (2005). Introducing Environmental Variables in Nonparametric Frontier Models: a Probabilistic Approach. Journal of Productivity Analysis, 24(1):93121.

Daraio, C. and Simar, L. (2007a). Advanced Robust and Nonparametric Methods in Efficiency Analysis - Methodology and Applications. Springer US. 
Daraio, C. and Simar, L. (2007b). Conditional nonparametric frontier models for convex and nonconvex technologies: a unifying approach. Journal of Productivity Analysis, 28(1):1332 .

Daraio, C., Simar, L., and Wilson, P. W. (2015). Testing the \&quot;separability\&quot; condition in two-stage nonparametric models of production. LEM Papers Series 2015/21, Laboratory of Economics and Management (LEM), Sant'Anna School of Advanced Studies, Pisa, Italy.

De Borger, B. and Kerstens, K. (1996). Cost efficiency of belgian local governments: A comparative analysis of fdh, dea, and econometric approaches. Regional science and urban economics, 26(2):145-170.

De Witte, K. and Geys, B. (2011). Evaluating efficient public good provision: Theory and evidence from a generalised conditional efficiency model for public libraries. Journal of Urban Economics, 69(3):319-327.

De Witte, K. and Kortelainen, M. (2013). What explains the performance of students in a heterogeneous environment? conditional efficiency estimation with continuous and discrete environmental variables. Applied Economics, 45(17):2401-2412.

Debreu, G. (1951). The coefficient of resource utilization. Econometrica, 19:273-292.

D'Inverno, G., Carosi, L., and Ravagli, L. (2018). Global public spending efficiency in tuscan municipalities. Socio-Economic Planning Sciences, 61:102 - 113. Recent developments on the use of DEA in the public sector.

D'Inverno, G. and De Witte, K. (2020). Service level provision in municipalities: A flexible directional distance composite indicator. European Journal of Operational Research, 286(3):1129 - 1141.

Farrell, M. (1957). The measurement of productive efficiency. Journal of the Royal Statistical Society, 120:253-290.

Fried, H., Knox Lovell, C., and Schmidt, S. (2008). The Measurement of Productive Efficiency and Productivity Growth. Oxford University Press, Oxford.

Friehe, T., Müller, H., and Neumeier, F. (2020). Media's role in the making of a democrat: Evidence from east germany. Journal of Comparative Economics. 
Funke, M., Schularick, M., and Trebesch, C. (2016). Going to extremes: Politics after financial crises, 1870-2014. European Economic Review, 88:227 - 260. SI: The Post-Crisis Slump.

Gerling, L. and Kellermann, K. L. (2019). The Impact of Election Information Shocks on Populist Party Preferences: Evidence from Germany. Working Papers 3/2019, Center for Interdisciplinary Economics.

Geys, B., Heinemann, F., and Kalb, A. (2010). Voter involvement, fiscal autonomy and public sector efficiency: Evidence from German municipalities. European Journal of Political Economy, 26(2):265-278.

Geys, B. and Revelli, F. (2009). Decentralization, Competition and the local tax mix: evidence from Flanders. Working Papers 2009/17, Institut d'Economia de Barcelona (IEB).

Gherghina, S. and Kopecký, P. (2016). Politicization of administrative elites in western europe: an introduction. Acta Politica, 51(0):407-412.

Guiso, L., H. H. M. M. and Sonno, T. (2020). Populism: Demand and Supply. Technical report, Bocconi University Mimeo.

Guiso, L., Herrera, H., Morelli, M., and Sonno, T. (2017). Demand and supply of populism. CEPR Discussion Papers 11871, C.E.P.R. Discussion Papers.

Havlík, V. and Voda, P. (2018). Cleavages, protest or voting for hope? the rise of centrist populist parties in the czech republic. Swiss Political Science Review, 24(2):161-186.

Heinisch, R. (2003). Success in opposition-failure in government: explaining the performance of right-wing populist parties in public office. West European Politics, 26(3):91-130.

Hibbs, D. A. (1977). Political parties and macroeconomic policy. American Political Science Review, 71(4):1467-1487.

Hooghe, L., Marks, G., Schakel, A. H., Osterkatz, S. C., Niedzwiecki, S., and ShairRosenfield, S. (2016). Measuring Regional Authority: A Postfunctionalist Theory of Governance (Vol. 1). Oxford University Press, Oxford.

Jäger, P. and Schmidt, T. (2016). The political economy of public investment when population is aging: A panel cointegration analysis. European Journal of Political Economy, $43(\mathrm{C}): 145-158$. 
Kane, C. and McCulloch, C. (2017). Populism and Foreign Policy: Deepening Divisions and Decreasing Efficiency. Global Politics Review, 3(2):39-52.

Kerstens, K. and Eeckaut, P. V. (1999). Estimating returns to scale using non-parametric deterministic technologies: A new method based on goodness-of-fit. European Journal of Operational Research, 113(1):206 - 214.

Martimort, D., De Donder, P., and De Villemeur, E. B. (2005). An incomplete contract perspective on public good provision. Journal of Economic Surveys, 19(2):149-180.

Melyn, W. and Moesen, W. (1991). Towards a synthetic indicator of macroeconomic performance: Unequal weighting when limited information is available.

Ministry of Finance of the Czech Republic (2020). Hospodaření územních rozpočtů za rok 2019.

Narbón-Perpiñá, I. and De Witte, K. (2018a). Local governments' efficiency: a systematic literature review - part i. International Transactions in Operational Research, 25(2):431468.

Narbón-Perpiñá, I. and De Witte, K. (2018b). Local governments' efficiency: a systematic literature review - part ii. International Transactions in Operational Research, 25(4):11071136.

Niskanen, W. A. (1968). The peculiar economics of bureaucracy. The American Economic Review, 58(2):293-305.

OECD (2019). General government spending (indicator). Paris: OECD Publishing.

Parliament of the Czech Republic (1997). Act no. 13/1997 coll. on roads.

Poterba, J. M. (1997). Demographic structure and the political economy of public education. Journal of Policy Analysis and Management, 16(1):48-66.

Sasso, G. and Morelli, M. (2020). Bureaucrats under Populism. Technical report, Bocconi University Mimeo.

Simar, L. and Wilson, P. (2011). Two-stage DEA: caveat emptor. Journal of Productivity Analysis, 36(2):205-218.

The World Bank (2017). Database of political institutions. 
Titl, V. and Geys, B. (2019). Political donations and the allocation of public procurement contracts. European Economic Review, 111:443-458.

Titl, V., Witte, K. D., and Geys, B. (2019). Political donations, public procurement and government efficiency. CESifo Working Paper Series 7591, CESifo Group Munich.

Transparency International (2019). The corruption perseptions index 2018.

Wagner, A. (1890). Finanzwissenschaft. C.F. Winter, Leipzig, Germany.

Yatchew, A. (1998). Nonparametric regression techniques in economics. Journal of Economic Literature, 36(2):669-721.

Ziller, C. and Goodman, S. W. (2020). Local government efficiency and anti-immigrant violence. The Journal of Politics, 0(0):000-000. 


\section{Appendix}

\section{A Raw output indicators}

Table OA.1: Indicators of outputs in three policy domains

\begin{tabular}{|c|c|c|c|c|c|c|c|}
\hline All variables per 1000 inhabitants & $\mathrm{N}$ & Mean & St. Dev. & Min & $\operatorname{Pctl}(25)$ & $\operatorname{Pctl}(75)$ & Max \\
\hline \multicolumn{8}{|l|}{ Panel I: Education output indicators } \\
\hline Nr. of kindergartens & 143 & 0.502 & 0.070 & 0.376 & 0.452 & 0.554 & 0.615 \\
\hline Nr. of teachers in kindergartens & 143 & 2.534 & 0.251 & 2.021 & 2.348 & 2.755 & 2.980 \\
\hline Nr. of children in kindergartens & 32.216 & 2.977 & 26.472 & 29.694 & 34.800 & 37.090 & \\
\hline Nr. of primary schools & 143 & 0.427 & 0.054 & 0.335 & 0.381 & 0.478 & 0.526 \\
\hline Nr. of teachers in primary schools & 143 & 5.846 & 0.274 & 5.345 & 5.649 & 6.018 & 6.584 \\
\hline Nr. of students in primary schools & 81.645 & 4.265 & 72.857 & 78.732 & 84.632 & 92.089 & \\
\hline Nr. of secondary schools & 143 & 0.131 & 0.017 & 0.093 & 0.116 & 0.147 & 0.176 \\
\hline Nr. of teachers in secondary schools & 143 & 4.067 & 0.525 & 2.672 & 3.737 & 4.513 & 4.906 \\
\hline Nr. of students in secondary schools & 143 & 47.118 & 7.125 & 29.483 & 41.934 & 53.608 & 58.749 \\
\hline \multicolumn{8}{|l|}{ Panel II: Healthcare output indicators } \\
\hline Nr. of doctors & 143 & 4.059 & 0.504 & 3.109 & 3.689 & 4.487 & 5.385 \\
\hline Nr. of hospitals & 143 & 0.017 & 0.003 & 0.012 & 0.014 & 0.019 & 0.025 \\
\hline Nr. of beds hospitals & 143 & 5.450 & 0.654 & 4.110 & 4.917 & 6.023 & 6.975 \\
\hline Nr. of spec. medical institutes & 143 & 0.015 & 0.006 & 0.007 & 0.010 & 0.017 & 0.029 \\
\hline Nr. of beds in medical institutes & 143 & 2.020 & 0.867 & 0.519 & 1.357 & 2.551 & 4.324 \\
\hline \multicolumn{8}{|c|}{ Panel III: Infrastructure output indicators } \\
\hline Roads class 2 in $\mathrm{kms}$ & 143 & 1.668 & 0.711 & 0.599 & 1.107 & 1.889 & 3.201 \\
\hline Roads class 3 in $\mathrm{kms}$ & 143 & 3.938 & 1.377 & 1.513 & 3.295 & 4.980 & 6.032 \\
\hline Length railways in $\mathrm{kms}$ & 143 & 1.094 & 0.324 & 0.534 & 0.936 & 1.264 & 1.665 \\
\hline
\end{tabular}

Notes: Dataset covers years 2007 to 2017. Source: Authors' elaboration based on Czech Statistical Office. 


\section{B Quality measures}

Table OA.2: Quality measures

\begin{tabular}{lccccccc}
\hline \hline & $\mathrm{N}$ & Mean & St. Dev. & Min & $\operatorname{Pctl}(25)$ & $\operatorname{Pctl}(75)$ & Max \\
\hline PISA test scores & 143 & 495.524 & 21.483 & 442 & 484.9 & 509 & 534 \\
Deaths & 143 & 0.003 & 0.0003 & 0.002 & 0.003 & 0.003 & 0.004 \\
Traffic accidents & 143 & 0.009 & 0.004 & 0.003 & 0.006 & 0.010 & 0.020
\end{tabular}

Notes: Dataset covers years 2007 to 2017. PISA test scores are the average of PISA test scores in given regions and years. Death rate takes into account death caused by cancer or heart attack and is calculated per capita. Traffic accidents are traffic accidents reported to the police in a given year and region. Source: Authors' elaboration based on the Czech Statistical Office and the Czech school inspection reports.

\section{The choice of $\mathrm{m}$ for the DEA models}

Figure OA.1: The share of super-efficient observations and $m$ - education

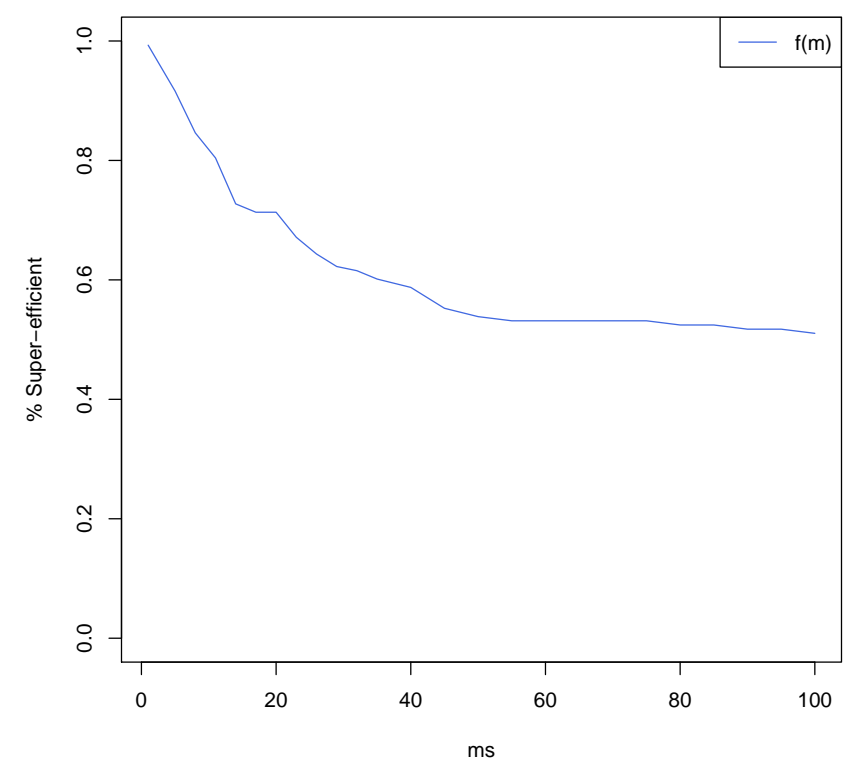

Notes: The figure shows the shares of super-efficient observations for the Benefit-of-the-Doubt estimation of the composite indicator for education output depending on the choice of $m$. 
Figure OA.2: The share of super-efficient observations and $m$ - healthcare

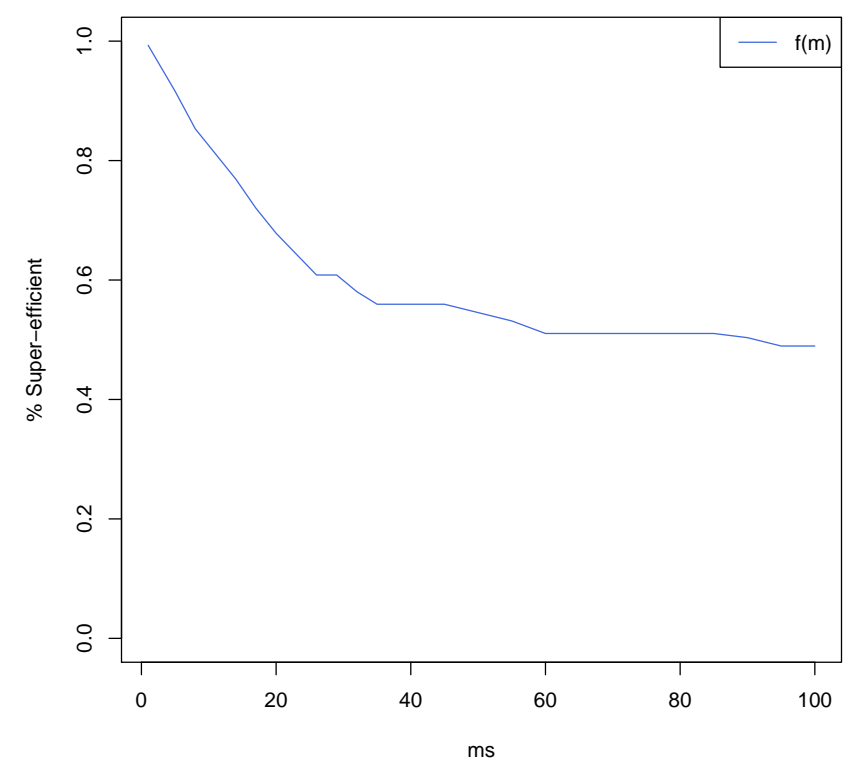

Notes: The figure shows the shares of super-efficient observations for the Benefit-of-the-Doubt estimation of the composite indicator for healthcare output depending on the choice of $m$. 
Figure OA.3: The share of super-efficient observations and $m$ - infrastructure

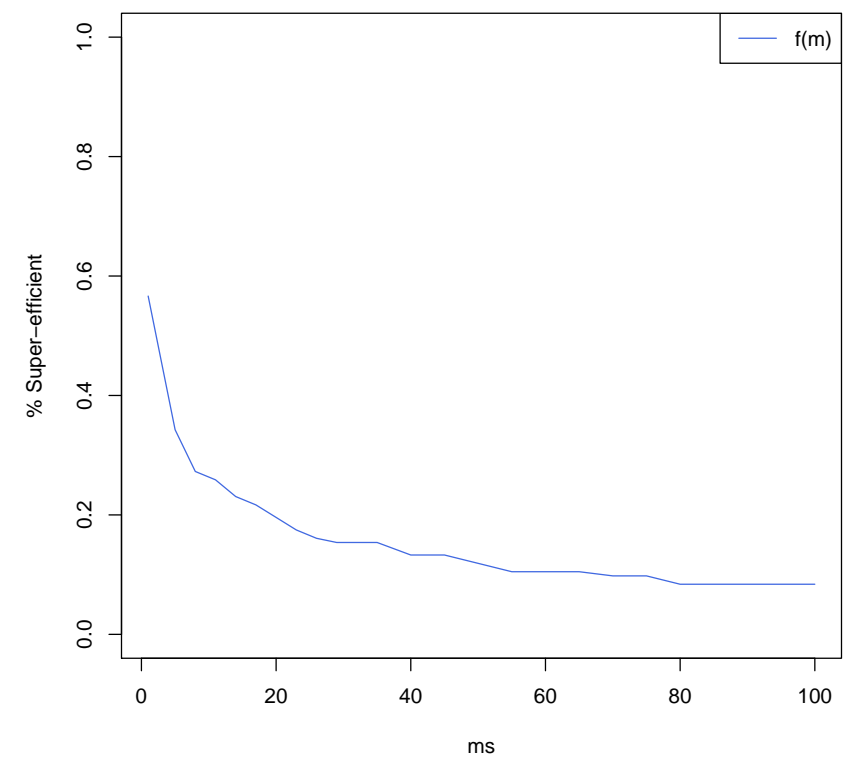

Notes: The figure shows the shares of super-efficient observations for the Benefit-of-the-Doubt estimation of the composite indicator for infrastructure output depending on the choice of $m$. 


\section{Detailed results for correlations within policy do- mains}

\section{D.1 Education}

\section{D.1.1 Left-wing}

Table OA.3: Correlation between the share of left-wing parties and the regional efficiency scores

\begin{tabular}{llllll}
\hline Variable & $(1)$ & $(2)$ & $(3)$ & $(4)$ & $(5)$ \\
\hline Mean eff. score & 0.124 & 0.958 & 0.959 & 0.955 & 0.958 \\
SD eff. score & 0.237 & 0.055 & 0.055 & 0.055 & 0.056 \\
Min score & 0.042 & 0.840 & 0.841 & 0.838 & 0.841 \\
Max score & 1.0 & 1.074 & 1.092 & 1.070 & 1.107 \\
Observations & 143 & 143 & 143 & 143 & 143 \\
& & & & & \\
Share of Left & - & Favorable & Favorable*** & Favorable*** & Favorable*** \\
Year time trend & NO & NO & YES & NO & YES \\
Regional controls & NO & NO & NO & YES & YES \\
\hline
\end{tabular}

Notes: The table shows the results from a set of unconditional and conditional DEA models. Share of Left is defined as the share of left-wing regional councillors on all councillors in region $i$ and year $t$. Year time trend is a continuous variable across the years in our sample. Region controls include the revenue of regional governments per capita, the share of youth, and the share of elderly. ${ }^{* * *} \mathrm{p}<0.01,{ }^{* *} \mathrm{p}<0.05,{ }^{*} \mathrm{p}<0.1$ 


\section{D.1.2 Populist}

Table OA.4: Correlation between the share of populist parties and the regional efficiency scores

\begin{tabular}{llllll}
\hline Variable & $(1)$ & $(2)$ & $(3)$ & $(4)$ & $(5)$ \\
\hline Mean eff. score & 0.124 & 0.960 & 0.959 & 0.961 & 0.958 \\
SD eff. score & 0.237 & 0.056 & 0.055 & 0.056 & 0.055 \\
Min score & 0.042 & 0.839 & 0.837 & 0.839 & 0.837 \\
Max score & 1.0 & 1.088 & 1.090 & 1.097 & 1.094 \\
Observations & 143 & 143 & 143 & 143 & 143 \\
& & & & & \\
Share of Populist & - & Favorable & Unfavorable & Unfavorable & Unfavorable*** \\
Year time trend & NO & NO & YES & NO & YES \\
Regional controls & NO & NO & NO & YES & YES \\
\hline
\end{tabular}

Notes: The table shows the results from a set of unconditional and conditional DEA models. Share of Populist is defined as the share of regional councillors from populist parties on all councillors in region $i$ and year $t$. Year time trend is a continuous variable across the years in our sample. Region controls include the revenue of regional governments per capita, the share of youth, and the share of elderly. $* * * \mathrm{p}<0.01,{ }^{* *} \mathrm{p}<0.05,{ }^{*} \mathrm{p}<0.1$ 


\section{D.1.3 Extremist}

Table OA.5: Correlation between the share of extremist parties and the regional efficiency scores

\begin{tabular}{llllll}
\hline Variable & $(1)$ & $(2)$ & $(3)$ & $(4)$ & $(5)$ \\
\hline Mean eff. score & 0.124 & 0.958 & 0.956 & 0.957 & 0.956 \\
SD eff. score & 0.237 & 0.056 & 0.055 & 0.056 & 0.055 \\
Min score & 0.042 & 0.838 & 0.836 & 0.837 & 0.838 \\
Max score & 1.0 & 1.077 & 1.080 & 1.085 & 1.084 \\
Observations & 143 & 143 & 143 & 143 & 143 \\
& & & & & \\
Share of Extremist & - & Favorable** & Unfavorable & Favorable* & Favorable \\
Year time trend & NO & NO & YES & NO & YES \\
Regional controls & NO & NO & NO & YES & YES \\
\hline
\end{tabular}

Notes: The table shows the results from a set of unconditional and conditional DEA models. Share of Extremist is defined as the share of regional councillors from extremist parties on all councillors in region $i$ and year $t$. Year time trend is a continuous variable across the years in our sample. Region controls include the revenue of regional governments per capita, the share of youth, and the share of elderly. $* * * \mathrm{p}<0.01,{ }^{* *} \mathrm{p}<0.05,{ }^{*} \mathrm{p}<0.1$ 


\section{D.2 Healthcare}

\section{D.2.1 Left-wing}

Table OA.6: Correlation between the share of left-wing parties and the regional efficiency scores

\begin{tabular}{llllll}
\hline Variable & $(1)$ & $(2)$ & $(3)$ & $(4)$ & $(5)$ \\
\hline Mean eff. score & 0.360 & 0.935 & 0.933 & 0.934 & 0.932 \\
SD eff. score & 0.116 & 0.080 & 0.080 & 0.080 & 0.079 \\
Min score & 0.035 & 0.731 & 0.728 & 0.731 & 0.726 \\
Max score & 1.0 & 1.104 & 1.101 & 1.117 & 1.074 \\
Observations & 143 & 143 & 143 & 143 & 143 \\
& & & & & \\
Share of Left & - & Unfavorable & Favorable & Favorable** & Unfavorable*** \\
Year time trend & NO & NO & YES & NO & YES \\
Regional controls & NO & NO & NO & YES & YES \\
\hline
\end{tabular}

Notes: The table shows the results from a set of unconditional and conditional DEA models. Share of Left is defined as the share of left-wing regional councillors on all councillors in region $i$ and year $t$. Year time trend is a continuous variable across the years in our sample. Region controls include the revenue of regional governments per capita, the share of youth, and the share of elderly. ${ }^{* * *} \mathrm{p}<0.01,{ }^{* *} \mathrm{p}<0.05,{ }^{*} \mathrm{p}<0.1$ 


\section{D.2.2 Populist}

Table OA.7: Correlation between the share of populist parties and the regional efficiency scores

\begin{tabular}{llllll}
\hline Variable & $(1)$ & $(2)$ & $(3)$ & $(4)$ & $(5)$ \\
\hline Mean eff. score & 0.360 & 0.930 & 0.933 & 0.929 & 0.931 \\
SD eff. score & 0.116 & 0.078 & 0.079 & 0.078 & 0.079 \\
Min score & 0.035 & 0.730 & 0.728 & 0.728 & 0.727 \\
Max score & 1.0 & 1.076 & 1.077 & 1.067 & 1.077 \\
Observations & 143 & 143 & 143 & 143 & 143 \\
& & & & & \\
Share of Populist & - & Favorable & Favorable & Favorable & Favorable \\
Year time trend & NO & NO & YES & NO & YES \\
Regional controls & NO & NO & NO & YES & YES \\
\hline
\end{tabular}

Notes: The table shows the results from a set of unconditional and conditional DEA models. Share of Populist is defined as the share of regional councillors from populist parties on all councillors in region $i$ and year $t$. Year time trend is a continuous variable across the years in our sample. Region controls include the revenue of regional governments per capita, the share of youth, and the share of elderly. $* * * \mathrm{p}<0.01, * * \mathrm{p}<0.05, * \mathrm{p}<0.1$ 


\section{D.2.3 Extremist}

Table OA.8: Correlation between the share of extremist parties and the regional efficiency scores

\begin{tabular}{llllll}
\hline Variable & $(1)$ & $(2)$ & $(3)$ & $(4)$ & $(5)$ \\
\hline Mean eff. score & 0.360 & 0.938 & 0.938 & 0.938 & 0.939 \\
SD eff. score & 0.116 & 0.080 & 0.080 & 0.080 & 0.079 \\
Min score & 0.035 & 0.728 & 0.735 & 0.728 & 0.729 \\
Max score & 1.0 & 1.067 & 1.066 & 1.062 & 1.076 \\
Observations & 143 & 143 & 143 & 143 & 143 \\
& & & & & \\
Share of Extremist & - & Favorable & Favorable & Unfavorable & Favorable \\
Year time trend & NO & NO & YES & NO & YES \\
Regional controls & NO & NO & NO & YES & YES \\
\hline
\end{tabular}

Notes: The table shows the results from a set of unconditional and conditional DEA models. Share of Extremist is defined as the share of regional councillors from extremist parties on all councillors in region $i$ and year $t$. Year time trend is a continuous variable across the years in our sample. Region controls include the revenue of regional governments per capita, the share of youth, and the share of elderly. $* * * \mathrm{p}<0.01,{ }^{* *} \mathrm{p}<0.05,{ }^{*} \mathrm{p}<0.1$ 


\section{D.3 Infrastructure}

\section{D.3.1 Left-wing}

Table OA.9: Correlation between the share of left-wing parties and the regional efficiency scores

\begin{tabular}{llllll}
\hline Variable & $(1)$ & $(2)$ & $(3)$ & $(4)$ & $(5)$ \\
\hline Mean eff. score & 0.561 & 0.452 & 0.450 & 0.456 & 0.448 \\
SD eff. score & 0.199 & 0.298 & 0.297 & 0.300 & 0.295 \\
Min score & 0.298 & 0.046 & 0.046 & 0.046 & 0.045 \\
Max score & 1.0 & 1.073 & 1.068 & 1.076 & 1.049 \\
Observations & 143 & 143 & 143 & 143 & 143 \\
& & & & & \\
Share of Left & - & Favorable** & Favorable** & Favorable** & Favorable \\
Year time trend & NO & NO & YES & NO & YES \\
Regional controls & NO & NO & NO & YES & YES \\
\hline
\end{tabular}

Notes: The table shows the results from a set of unconditional and conditional DEA models. Share of Left is defined as the share of left-wing regional councillors on all councillors in region $i$ and year $t$. Year time trend is a continuous variable across the years in our sample. Region controls include the revenue of regional governments per capita, the share of youth, and the share of elderly. ${ }^{* * *} \mathrm{p}<0.01,{ }^{* *} \mathrm{p}<0.05,{ }^{*} \mathrm{p}<0.1$ 


\section{D.3.2 Populist}

Table OA.10: Correlation between the share of populist parties and the regional efficiency scores

\begin{tabular}{llllll}
\hline Variable & $(1)$ & $(2)$ & $(3)$ & $(4)$ & $(5)$ \\
\hline Mean eff. score & 0.561 & 0.445 & 0.444 & 0.445 & 0.444 \\
SD eff. score & 0.199 & 0.292 & 0.293 & 0.292 & 0.294 \\
Min score & 0.298 & 0.045 & 0.045 & 0.045 & 0.045 \\
Max score & 1.0 & 1.043 & 1.046 & 1.046 & 1.057 \\
Observations & 143 & 143 & 143 & 143 & 143 \\
& & & & & \\
Share of Populist & - & Favorable*** & Favorable* & Favorable*** & Favorable \\
Year time trend & NO & NO & YES & NO & YES \\
Regional controls & NO & NO & NO & YES & YES \\
\hline
\end{tabular}

Notes: The table shows the results from a set of unconditional and conditional DEA models. Share of Populist is defined as the share of regional councillors from populist parties on all councillors in region $i$ and year $t$. Year time trend is a continuous variable across the years in our sample. Region controls include the revenue of regional governments per capita, the share of youth, and the share of elderly. $* * * \mathrm{p}<0.01,{ }^{* *} \mathrm{p}<0.05,{ }^{*} \mathrm{p}<0.1$ 


\section{D.3.3 Extremist}

Table OA.11: Correlation between the share of extremist parties and the regional efficiency scores

\begin{tabular}{llllll}
\hline Variable & $(1)$ & $(2)$ & $(3)$ & $(4)$ & $(5)$ \\
\hline Mean eff. score & 0.561 & 0.440 & 0.442 & 0.443 & 0.444 \\
SD eff. score & 0.199 & 0.289 & 0.290 & 0.290 & 0.293 \\
Min score & 0.298 & 0.045 & 0.045 & 0.045 & 0.045 \\
Max score & 1.0 & 1.024 & 1.029 & 1.023 & 1.045 \\
Observations & 143 & 143 & 143 & 143 & 143 \\
& & & & & \\
Share of Extremist & - & Favorable*** & Favorable & Favorable*** & Favorable \\
Year time trend & NO & NO & YES & NO & YES \\
Regional controls & NO & NO & NO & YES & YES \\
\hline
\end{tabular}

Notes: The table shows the results from a set of unconditional and conditional DEA models. Share of Extremist is defined as the share of regional councillors from extremist parties on all councillors in region $i$ and year $t$. Year time trend is a continuous variable across the years in our sample. Region controls include the revenue of regional governments per capita, the share of youth, and the share of elderly. $* * * \mathrm{p}<0.01,{ }^{* *} \mathrm{p}<0.05,{ }^{*} \mathrm{p}<0.1$ 